\title{
Changes in urinary nanocrystallites in calcium oxalate stone formers before and after potassium citrate intake
}

This article was published in the following Dove Press journal:

International Journal of Nanomedicine

28 February 2013

Number of times this article has been viewed

\author{
Chao-Yang Duan' \\ Zhi-Yue $\mathrm{Xia}^{2}$ \\ Guang-Na Zhang ${ }^{2}$ \\ Bao-Song Gui' \\ Jun-Fa Xue ${ }^{2}$ \\ Jian-Ming Ouyang ${ }^{2}$ \\ 'Department of Nephrology, the \\ Second Hospital of Xi'an Jiaotong \\ University, Xi'an, People's Republic of \\ China; ${ }^{2}$ Institute of Biomineralization \\ and Lithiasis Research, Jinan \\ University, Guangzhou, People's \\ Republic of China
}

Correspondence: Bao-Song Gui Department of Nephrology, the Second Hospital of Xi'an Jiaotong University, Xi'an 710004, People's Republic of China Email guibsdoctor@sina.com

Jian-Ming Ouyang Institute of Biomineralization and Lithiasis Research, Jinan University, Guangzhou 510632, People's Republic of China Email toyjm@jnu.edu.cn

\begin{abstract}
The property changes of urinary nanocrystallites in 13 patients with calcium oxalate $(\mathrm{CaOx})$ stones were studied before and after ingestion of potassium citrate $\left(\mathrm{K}_{3} \mathrm{cit}\right)$, a therapeutic drug for stones. The analytical techniques included nanoparticle size analysis, transmission electron microscopy, X-ray diffraction, and Fourier-transform infrared spectroscopy. The studied properties included the components, morphologies, zeta potentials, particle size distributions, light intensity autocorrelation curves, and polydispersity indices (PDIs) of the nanocrystallites. The main components of the urinary nanocrystallites before $\mathrm{K}_{3}$ cit intake included uric acid, $\beta$-calcium phosphate, and calcium oxalate monohydrate. After $\mathrm{K}_{3}$ cit intake, the quantities, species, and percentages of aggregated crystals decreased, whereas the percentages of monosodium urate and calcium oxalate dehydrate increased, and some crystallites became blunt. Moreover, the urinary $\mathrm{pH}$ increased from $5.96 \pm 0.43$ to $6.46 \pm 0.50$, the crystallite size decreased from $524 \pm 320 \mathrm{~nm}$ to $354 \pm 173 \mathrm{~nm}$, and the zeta potential decreased from $-4.85 \pm 2.87 \mathrm{mV}$ to $-8.77 \pm 3.03 \mathrm{mV}$. The autocorrelation curves became smooth, the decay time decreased from $11.4 \pm 3.2 \mathrm{~ms}$ to $4.3 \pm 1.7 \mathrm{~ms}$, and the PDI decreased from $0.67 \pm 0.14$ to $0.53 \pm 0.19$. These changes helped inhibit $\mathrm{CaOx}$ calculus formation.
\end{abstract}

Keywords: nanotechnology, zeta potential, aggregation

\section{Introduction}

Calcium oxalate $(\mathrm{CaOx})$ is the major component of urinary stones. From a chemical perspective, $\mathrm{CaOx}$ stone formation is closely related to: high levels of urine calcium and urine oxalic acid; nucleation, growth, and aggregation of $\mathrm{CaOx}$ crystals; and adhesion between crystals and renal tubular epithelial cells. ${ }^{1-3}$ Therefore, the crystallites in urine are crucial factors affecting the formation of uroliths. ${ }^{4-6}$

Previous studies ${ }^{5,6}$ have found differences between the urinary crystallites $(<1000 \mathrm{~nm}$ in size) of patients with urolithiasis and healthy subjects without any urolithiasis history. These studies concluded that the morphology, particle size, aggregation, and crystal phase of nanocrystallites in the urine of lithogenic patients remarkably differ from those of healthy persons. The urinary crystallites of healthy subjects are more stable than those of the patients. The results suggested that rounding nanocrystallites, diminishing their size differential, and decreasing their aggregation in urine by physical and chemical methods may prevent urinary stone formation.

Potassium citrate $\left(\mathrm{K}_{3}\right.$ cit) is the main drug used in treating and preventing the formation of $\mathrm{CaOx}$ stones. $^{7}$ After $\mathrm{K}_{3}$ cit intake, the urine may be alkalized and the excretion of urinary citrate thus increases. Citrate can combine with calcium ions and form a soluble chelate that reduces the supersaturation of $\mathrm{CaOx}$ in urine; thus, the 
nucleation, growth, and aggregation of $\mathrm{CaOx}$ crystals are inhibited and the formation and recurrence of $\mathrm{CaOx}$ stones are reduced. The recurrence rate among patients taking $\mathrm{K}_{3}$ cit is only $20 \%$ compared with those not taking $\mathrm{K}_{3}$ cit. $^{8}$

However, reports on the property changes of urinary crystallites from patients with $\mathrm{CaOx}$ stones before and after $\mathrm{K}_{3}$ cit intake are very limited. The relationship between these changes and the formation of stones is also unknown. Therefore, the property changes of urinary nanocrystallites were studied in 13 patients with history of $\mathrm{CaOx}$ stones ("CaOx stone formers") before and after $\mathrm{K}_{3}$ cit intake, to clarify the relationship between urinary crystallites and urolithiasis, and promote clinical suppression.

\section{Materials and methods}

\section{Reagents and instruments}

The absolute ethanol, sodium azide $\left(\mathrm{NaN}_{3}\right)$, and formaldehyde $(36 \%, v / v)$ used were of analytical purity. All glass vessels were cleaned with double-distilled water.

$\mathrm{X}$-ray diffraction (XRD) results were recorded on a D/ max- $\gamma$ A 2400 X-ray diffractometer (Rigaku, Tokyo, Japan). Samples were observed with a TECNAI-10 transmission electron microscope (TEM) (Royal Philips Electronics, Amsterdam, Netherlands), at an accelerating voltage of 100 kV. Image Pro Plus 5.02 software (Media Cybernetics, Rockville, MD, USA) was used to analyze the diameter and count the number of particles in the TEM images. A Nicolet 6700 Fourier-transform infrared (FT-IR) spectrometer (Thermo Fisher Scientific, Waltham, MA, USA), and a Zetasizer Nano ZS nanoparticle size and Zeta potential analyzer (Malvern Instruments Ltd, Malvern, UK) were also used.

\section{Collection and treatment of urine}

The participants in the study were 13 lithogenic patients (nine men and four women; mean age $=54.1$ years, range $=24-71$ years) and 13 randomly selected healthy humans with no prior history of urinary stones (nine men and four women; mean age $=38.6$ years, range $=23-56$ years ).

Fresh urine from the $\mathrm{CaOx}$-stone-forming patients was collected before and a week after $\mathrm{K}_{3}$ cit intake (dosage $=2.538 \mathrm{~g} / \mathrm{d})$. The citrate treatment lasted for 2 weeks, starting 2 days before surgery, and the urine was collected after 7 days of treatment. After detecting the $\mathrm{pH}, 2 \%(\mathrm{w} / \mathrm{v})$ $\mathrm{NaN}_{3}$ solution (10 mL/L urine sample) was added to the urine samples as antiseptic. Anhydrous alcohol $\left(\mathrm{V}_{\text {urine }}: \mathrm{V}_{\text {anhydrous }}\right.$ alcohol $=3: 2$ ) was then added to $30 \mathrm{~mL}$ of each urine sample, stirred, and left to stand for 30 minutes. The purpose of the addition of alcohol was to remove the proteins in the urine. Alcohol can denaturalize and deposit the proteins, which can interfere with the observation of urinary crystallites by TEM as well as with the identification of peaks by XRD and FT-IR. The urine was then filtered through a $1.2 \mu \mathrm{m}$ microporous membrane.

\section{Collection and component characterization of urinary calculus}

Urinary stones were collected after surgery, cleared with double-distilled water, and placed in a dust-free incubator at $50^{\circ} \mathrm{C}$ for drying. The urinary stones were then ground into powder with an agate mortar for XRD and FT-IR characterization. Results showed that the urinary stones were mainly composed of $\mathrm{CaOx}$ with a mass fraction of $90 \%$ to $100 \%$. The other components of the urinary stones included $\beta$-calcium phosphate and uric acid.

\section{Measurement of zeta potential $(\zeta)$ and particle size}

The above-filtered urine samples were ultrasonicated for 3 minutes to destroy any possible crystal agglomerations. Subsequently, to detect the $\zeta$ and particle sizes of the urinary crystallites, about $1.5 \mathrm{~mL}$ from each sample of treated urine was immediately injected into the cell of a $\zeta$ analyzer, and another $1.5 \mathrm{~mL}$ was injected into the cell of a nanoparticle size analyzer.

\section{Characterization of urine crystallite components \\ XRD and FT-IR detection of urinary crystallites}

About $100 \mu \mathrm{L}$ of spare urine from each sample was placed on clean glass slides using a microsyringe. The glass slides were then dried in an oven at $50^{\circ} \mathrm{C} \pm 5^{\circ} \mathrm{C}$ for 2 hours to volatilize the urine. This process was repeated three times. Nanocrystallites were then deposited onto the glass slides. Subsequently, the glass slides were slowly immersed in distilled water at a $45^{\circ}$ angle and gently shaken for 1 minute to remove the soluble fractions of sodium chloride and urea. After carefully removing the glass slides, water from the edge of the slides was dried using an absorbent paper, and the slides were again dried at $50^{\circ} \mathrm{C} \pm 5^{\circ} \mathrm{C}$ in a vacuum desiccator for 1 day, for further XRD and FT-IR characterization.

\section{TEM detection of urinary crystallites}

About $5 \mu \mathrm{L}$ of the above spare urine from each sample was placed in a copper mesh. The copper mesh was stored in a desiccator for 24 hours and then examined by TEM. 


\section{Determination of citric acid, gycosaminoglycans (GAGs), and uric acid (UA) in the urine}

The Alcian blue colorimetric method and ammonium metavanadate-assisted catalytic-kinetic spectrophotometry were used to detect the contents of GAGs and citrate in urine. ${ }^{9,10}$ Using a spectrophotometer, the UA content was determined by its ability to reduce Fe (III) to Fe (II), which can then coordinate with phenanthroline to produce orangered complexes. ${ }^{11}$

\section{Statistical analysis}

The experimental data were analyzed using SPSS version 16.0 software (IBM, Armonk, NY, USA). The experimental data were expressed as the mean \pm standard deviation. Data differences between two groups were analyzed by a $t$-test, and the $P$ value was used to assess the statistical significance. $P<0.05$ was deemed to indicate a significant difference, $P<0.01$ indicated an extremely significant difference, and $P>0.05$ indicated no significant difference.

\section{Results and discussion \\ Powder XRD analysis of urinary crystallites before and after $\mathrm{K}_{3}$ cit intake}

The urinary crystallites of all 13 cases of $\mathrm{CaOx}$ stone formers before and after $\mathrm{K}_{3}$ cit intake were analyzed using XRD. Three representative results are shown in Figure 1. The results show the following:

1. Before $\mathrm{K}_{3}$ cit intake, the main components of the urinary crystallites of the $\mathrm{CaOx}$ stone formers included UA, $\beta$-calcium phosphate, and calcium oxalate monohydrate (COM) (Figure 1A, C, and E).

The diffraction peaks located at $3.86,3.53$, and $2.73 \AA$ were assigned to the $(\overline{2} 11),(301)$, and (202) plane of UA, respectively. ${ }^{12}$ The peaks at $2.84,2.49$, and $1.98 \AA$ were assigned to the (121), (112), and (303) plane of COM, respectively. The diffraction peaks at $5.23,3.00$, and 2.65 $\AA$ were assigned to the (110), (300), and (1112) plane of $\beta$-calcium phosphate, respectively (Figures $1 \mathrm{~A}$ and $\mathrm{E}$ ).

2. After 1 week of $\mathrm{K}_{3}$ cit intake, the number of diffraction peaks of urinary crystallites decreased (Figure 1B, D, and F). This result showed that the species of urinary crystallites decreased after taking $\mathrm{K}_{3}$ cit. $^{13}$

3. The intensity of the diffraction peaks of urinary crystallites weakened after $\mathrm{K}_{3}$ cit intake. This result showed that the mass of crystallites significantly declined after $\mathrm{K}_{3}$ cit intake. $^{13}$
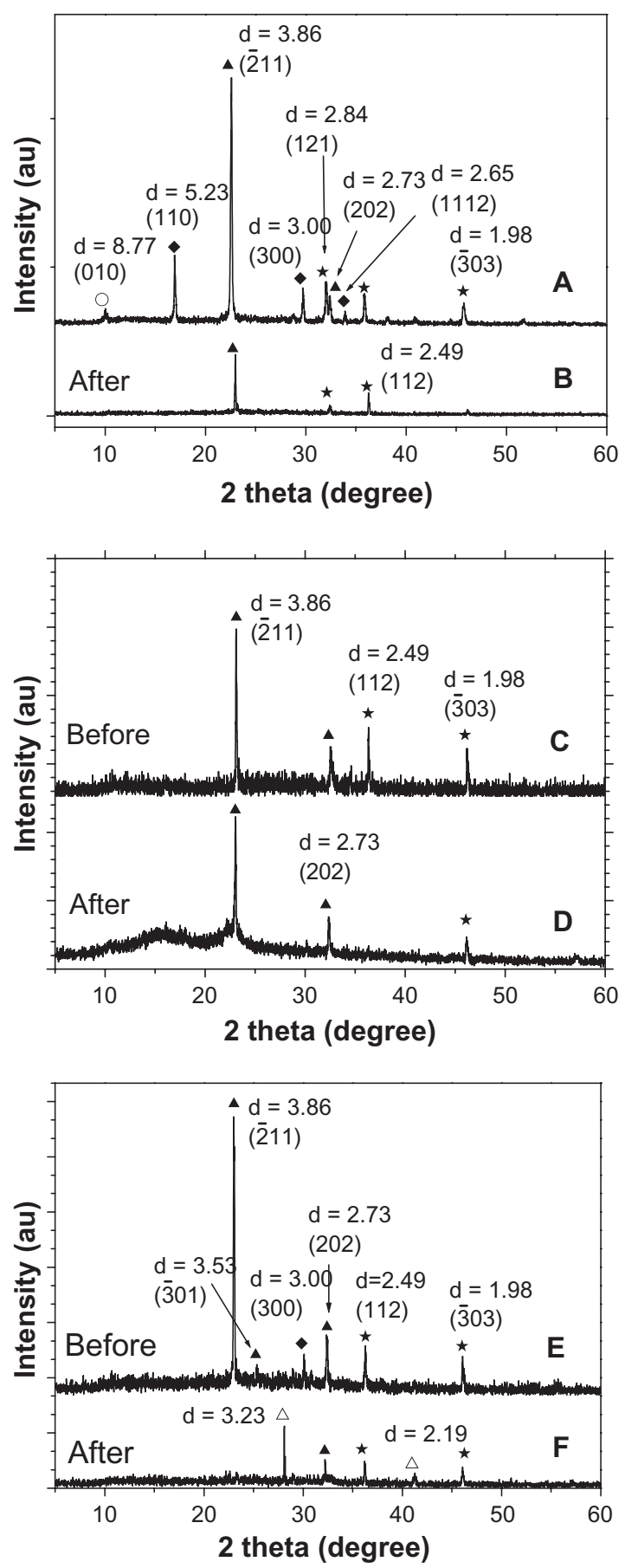

Figure I XRD patterns of urinary nanocrystallites of the three $\mathrm{CaO}$ stone-forming patients before (A, $\mathbf{C}$ and $\mathbf{E})$ and after (B, D and $\mathbf{F}) \mathrm{K}_{3}$ cit intake.

Notes: $\$$ : calcium oxalate monohydrate; $\boldsymbol{\Delta}$ : uric acid; $\triangle$ : monosodium urate; $\bullet: \beta-\mathrm{Ca}_{3}\left(\mathrm{PO}_{4}\right)_{2} ; \mathrm{O}: \mathrm{MgNH}_{4} \mathrm{PO}_{4} \cdot 6 \mathrm{H}_{2} \mathrm{O}$.

Abbreviations: $\mathrm{XRD}$, $\mathrm{X}$-ray diffraction; $\mathrm{CaOx}$, calcium oxalate; $\mathrm{K}_{3}$ cit, potassium citrate.

Compared with the XRD patterns of urinary crystallites before $\mathrm{K}_{3}$ cit intake, the diffraction peak of UA at $\mathrm{d}=3.86$ and $2.73 \AA$ abated (Figure 1B and D) or disappeared (Figure $1 \mathrm{~F}$ ) after $\mathrm{K}_{3}$ cit intake. This result indicated that the amount of UA in urine significantly decreased. 
The citrate excreted in urine after $\mathrm{K}_{3}$ cit intake can alkalize urine, which can increase the urine $\mathrm{pH}$ and transform the majority of UA to urate, whose larger solubility significantly reduces the mass of UA.

Similarly, the diffraction peaks of COM at 2.49 and $1.98 \AA$ also decreased (Figure 1B) or disappeared (Figure 1D and F), suggesting that the content of $\mathrm{COM}$ crystallites also decreased after $\mathrm{K}_{3}$ cit intake. $\mathrm{K}_{3}$ cit is a strong complex agent that can combine with $\mathrm{Ca}^{2+}$ ions to form soluble calcium citrate, which reduces the saturation degree of $\mathrm{CaOx}$ in urine thus inhibiting the formation of $\mathrm{CaOx}$ crystals. Consequently, the amount of $\mathrm{CaOx}$ crystallites in the urine decreased after $\mathrm{K}_{3}$ cit intake for 1 week.

4. After $\mathrm{K}_{3}$ cit intake, new diffraction peaks of monosodium urate appeared. As shown in Figure 1F, the diffraction peaks assigned to UA and COM abated or disappeared after $\mathrm{K}_{3}$ cit intake. However, new diffraction peaks appeared at 3.23 and $2.19 \AA$ because of the appearance of monosodium urate. ${ }^{14}$ These results indicated that monosodium urates were present in the urine.

\section{Representative FT-IR spectra of urinary crystallites before and after $\mathrm{K}_{3}$ cit intake}

The changes in urinary crystallites components were examined by FT-IR spectroscopy. The representative spectra are shown in Figure 2.

1. Before $\mathrm{K}_{3}$ cit intake, the peaks detected at 1668,1454 , and $524 \mathrm{~cm}^{-1}$ indicated the presence of UA. ${ }^{15,16}$ The peaks of coordinated water were located at $3488 \mathrm{~cm}^{-1}$ to $3219 \mathrm{~cm}^{-1}$. These broad peaks were attributed to the symmetrical stretching vibration and asymmetrical stretching vibration of $\mathrm{OH}^{-}$of coordinated water molecules. The peaks at 1332, 781, and $592 \mathrm{~cm}^{-1}$ were characteristic adsorptions of COM (Figures $2 \mathrm{C}$ and $\mathrm{E}$ ).

The absorption peaks of $\beta$-calcium phosphate were also detected in some samples. As shown in Figure 2A, $1160 \mathrm{~cm}^{-1}$ was attributed to the $\mathrm{O}-\mathrm{P}-\mathrm{O}$ symmetric stretching vibration and $1080 \mathrm{~cm}^{-1}$ was attributed to the $\mathrm{PO}_{4}^{3-}$ asymmetric vibration absorption peak. As shown in Figure 2C, $989 \mathrm{~cm}^{-1}$ was attributed to the $\mathrm{PO}_{4}^{3-}$ symmetric vibration absorption peak. ${ }^{17}$

Before $\mathrm{K}_{3}$ cit intake, the main components of urinary crystallites were UA, COM, and $\beta$-calcium phosphate, which were consistent with the XRD results.

2. The absorption peaks after $\mathrm{K}_{3}$ cit intake changed as follows (Figure 2B, D, and F):

a. The absorption peak intensity weakened or even disappeared. The number of absorption peaks was significantly
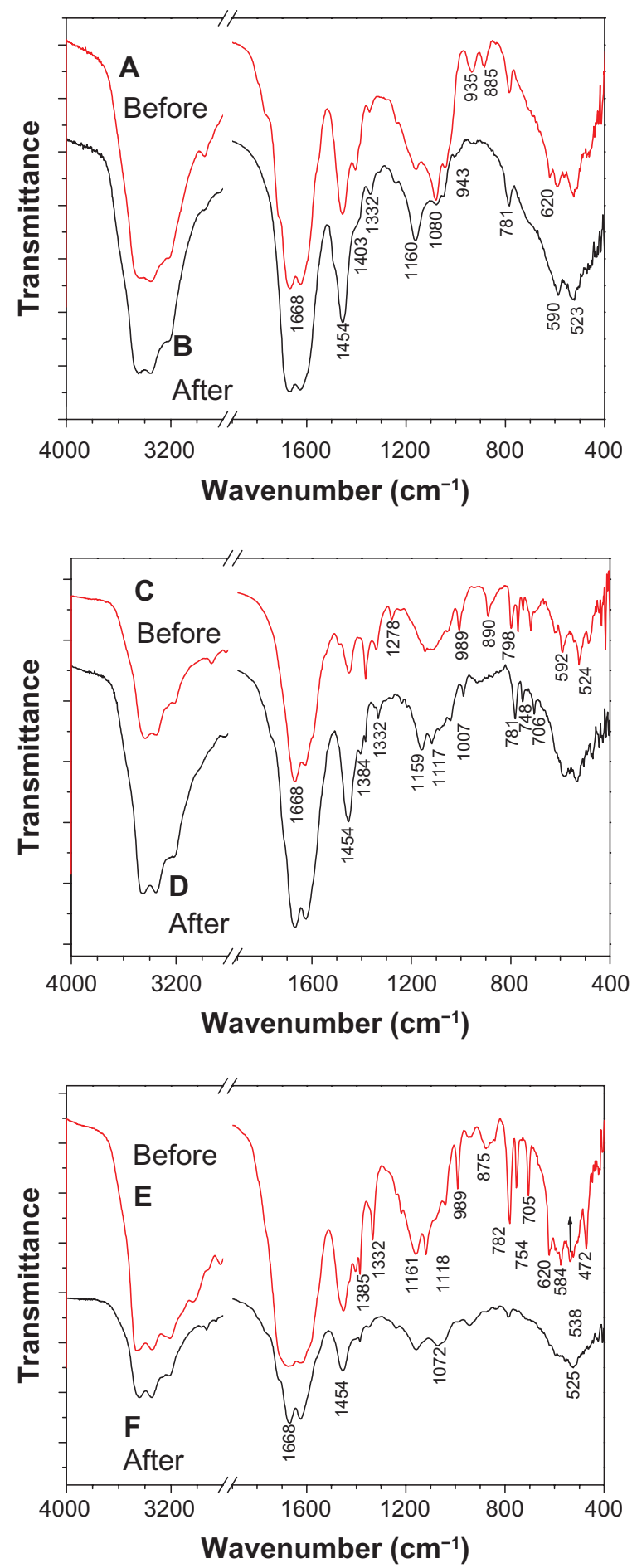

Figure 2 FT-IR spectra of urinary nanocrystallites of the three $\mathrm{CaOx}$ stone-forming patients before ( $\mathbf{A}, \mathbf{C}$, and $\mathbf{E})$ and after $(\mathbf{B}, \mathbf{D}$, and $\mathbf{F}) \mathrm{K}_{3}$ cit intake.

Abbreviations: FT-IR, Fourier-transform infrared (spectrometer); $\mathrm{CaOx}$, calcium oxalate; $\mathrm{K}_{3}$ cit, potassium citrate.

lower after $\mathrm{K}_{3}$ cit intake (Figure 2B) than before $\mathrm{K}_{3}$ cit intake (Figure 2A). The absorption peaks of the inplane bending vibration of $\mathrm{O}^{-} \mathrm{C}^{-} \mathrm{O}^{-}\left(\gamma_{a s}\left(\mathrm{COO}^{-}\right)\right)$at 935 and $885 \mathrm{~cm}^{-1}$ for COM disappeared, and the stretching vibration of $\mathrm{C}-\mathrm{N}$ for $\mathrm{UA}$ at $1403 \mathrm{~cm}^{-1}$ weakened. 
When comparing Figure 2C and D or Figure 2E and $\mathrm{F}$, the stretching vibration of $\mathrm{C}=\mathrm{O}$ of $\mathrm{COM}$ at 1384 and $1332 \mathrm{~cm}^{-1}$, the stretching vibration of $\mathrm{C}-\mathrm{C}$ of $\mathrm{COM}$ at $782 \mathrm{~cm}^{-1}$, the stretching vibration of $\mathrm{C}=\mathrm{O}$ of UA at $1118 \mathrm{~cm}^{-1}$, and the peaks of UA at $875,705,620,538$, and $472 \mathrm{~cm}^{-1}$ in the fingerprint region, all either weakened or disappeared.

b. After $\mathrm{K}_{3}$ cit intake, the absorption peaks of monosodium urate and $\beta$-calcium phosphate either appeared or increased in intensity. Before $\mathrm{K}_{3}$ cit intake (Figure 2C), only the symmetric stretching vibration peak of $\mathrm{O}-\mathrm{P}-\mathrm{O}$ at $1159 \mathrm{~cm}^{-1}$ and $\mathrm{PO}_{4}{ }^{3-}$ at $989 \mathrm{~cm}^{-1}$ were present. However, after $\mathrm{K}_{3}$ cit intake (Figure 2D), new absorption peaks appeared at $1007 \mathrm{~cm}^{-1}$ for phosphate, as well as at 2927 and $798 \mathrm{~cm}^{-1}$ for urate. ${ }^{18}$

Therefore, the FT-IR results were consistent with those of the XRD.

\section{Property changes of urine before and after $\mathrm{K}_{3}$ cit intake \\ Changes in citrate, GAGs, and UA excretion}

After $\mathrm{K}_{3}$ cit intake for 1 week, the citrate excretion from the urine of all 13 cases of $\mathrm{CaOx}$ stone formers increased from $264 \pm 74 \mathrm{mg} / \mathrm{L}$ to $381 \pm 109 \mathrm{mg} / \mathrm{L}$ (Figure $3 \mathrm{E}$ ), and UA excretion decreased from $563 \pm 91 \mathrm{mg} / \mathrm{L}$ to $393 \pm 86 \mathrm{mg} / \mathrm{L}$ (Figure 3F). No significant difference was observed before and after $\mathrm{K}_{3}$ cit intake $(P>0.05)$. However, the excretion of GAGs from urine increased from $5.18 \pm 0.82 \mathrm{mg} / \mathrm{L}$ to $11.81 \pm 1.62 \mathrm{mg} / \mathrm{L}$. These differences in GAGs excretion before and after $\mathrm{K}_{3}$ cit intake were significant $(P<0.05)$.

\section{Changes in urine $\mathrm{pH}$ before and after $\mathrm{K}_{3}$ cit intake}

Before $\mathrm{K}_{3}$ cit intake, the urine $\mathrm{pH}$ was between 5.2 and 6.7 (Figure 3A), with an average value of $5.96 \pm 0.43$ (Table 1). At 1 week post- $\mathrm{K}_{3}$ cit intake, the urine $\mathrm{pH}$ increased to an average value of $6.46 \pm 0.50$; however, this difference was not significant $(P>0.05)$. After $\mathrm{K}_{3}$ cit intake, the urine $\mathrm{pH}(6.46 \pm 0.50)$ was close to that of the healthy controls $(6.28 \pm 0.30)(P>0.05)$.

The increase in urine $\mathrm{pH}$ was caused by the increase of $\mathrm{K}_{3}$ cit excretion after $\mathrm{K}_{3}$ cit intake. $\mathrm{K}_{3}$ cit is an alkaline salt and can alkalize urine.

\section{Size changes of urinary crystallites before and after $\mathrm{K}_{3}$ cit intake}

The particle size distribution and average diameter of urinary nanocrystallites from the $13 \mathrm{CaOx}$ stone-forming patients before and after $\mathrm{K}_{3}$ cit intake were studied using a nanoparticle size analyzer. Before $\mathrm{K}_{3}$ cit intake, the average particle size of urinary nanocrystallites in the 13 cases was $524 \pm 320 \mathrm{~nm}$ (Figure 3B). After $\mathrm{K}_{3}$ cit intake for 1 week, the particle size decreased to $354 \pm 173 \mathrm{~nm}$. Figure 4 showed the particle size distribution of urinary crystallites of two $\mathrm{CaOx}$ stone patients before and after $\mathrm{K}_{3}$ cit intake. Before $\mathrm{K}_{3}$ cit intake, the peak particle size values were 688 and $106 \mathrm{~nm}$, with an average size of $293 \mathrm{~nm}$ (Figure 4A), as well as 7.5, 80, and $955 \mathrm{~nm}$, with an average size of $432 \mathrm{~nm}$ (Figure 4C), respectively. After $\mathrm{K}_{3}$ cit intake, the peak particle size values were accordingly reduced to 19,98 , and $394 \mathrm{~nm}$, with an average size of $146 \mathrm{~nm}$ (Figure 4B), as well as 29, 123, and $495 \mathrm{~nm}$, with an average size of $220 \mathrm{~nm}$ (Fig. 4D), respectively.

Citrate excretions in the urine increased from $264 \pm$ $74 \mathrm{mg} / \mathrm{L}$ before $\mathrm{K}_{3}$ cit intake to $381 \pm 109 \mathrm{mg} / \mathrm{L}$ at 1 week after commencing $\mathrm{K}_{3}$ cit intake (Figure $3 \mathrm{E}$ ). On one hand, as an inhibitor of $\mathrm{CaOx}$ crystallization, citrate can close the growth sites of $\mathrm{CaOx}$ crystals, thereby inhibiting the growth and aggregation of $\mathrm{CaOx}$ crystals and ultimately decreasing the size of urinary crystallites. On the other hand, $\mathrm{K}_{3}$ cit chelated $\mathrm{Ca}^{2+}$ ions and dissolved the $\mathrm{CaOx}$ crystallites.

\section{$\zeta$ change of urinary crystallites before and after $\mathrm{K}_{3}$ cit intake}

Figure $3 \mathrm{C}$ shows the $\zeta$ change of urinary crystallites from $\mathrm{CaOx}$ stone-forming patients before and after $\mathrm{K}_{3}$ cit intake. The average $\zeta$ value of urinary crystallites in the $13 \mathrm{CaOx}$ stone formers were $-4.85 \pm 2.87 \mathrm{mV}$ before $\mathrm{K}_{3}$ cit intake and $-8.77 \pm 3.03 \mathrm{mV}$ after $\mathrm{K}_{3}$ cit intake; the latter was close to the $\zeta$ value $-8.89 \pm 2.23 \mathrm{mV}$ of healthy subjects $(P>0.05)$. The $\zeta$ value became negative after $\mathrm{K}_{3}$ cit intake because of the following:

1. As shown in Figure 3E, the citrate excretion in urine was increased after $\mathrm{K}_{3}$ cit intake. As an anion inhibitor, citrate can be adsorbed on the positively charged surface of crystallites, such as COM, which can increase the negative charges on the crystallite surface. Thus, the $\zeta$ becomes negative.

2. After $\mathrm{K}_{3}$ cit intake, the excretion and activity of TammHorsfall protein (TH protein) increased. ${ }^{19} \mathrm{TH}$ protein is also an anionic protein that enables the $\zeta$ of $\mathrm{CaOx}$ crystals to turn negative.

3. After $\mathrm{K}_{3}$ cit intake, the urine $\mathrm{pH}$ increased, which subsequently increased the ionization of acidic substances and the amount of negatively charged anionic species in urine. For example, the increase in $\mathrm{pH}$ can promote the ionization of citric acid in urine, causing the concentration of trivalent anionic citrate $\left(\mathrm{cit}^{3-}\right)$ to increase. The $\mathrm{pH}$ increase can also convert uric acid into urate and cystine into its salt, thereby further increasing the number of negatively charged species. 
A
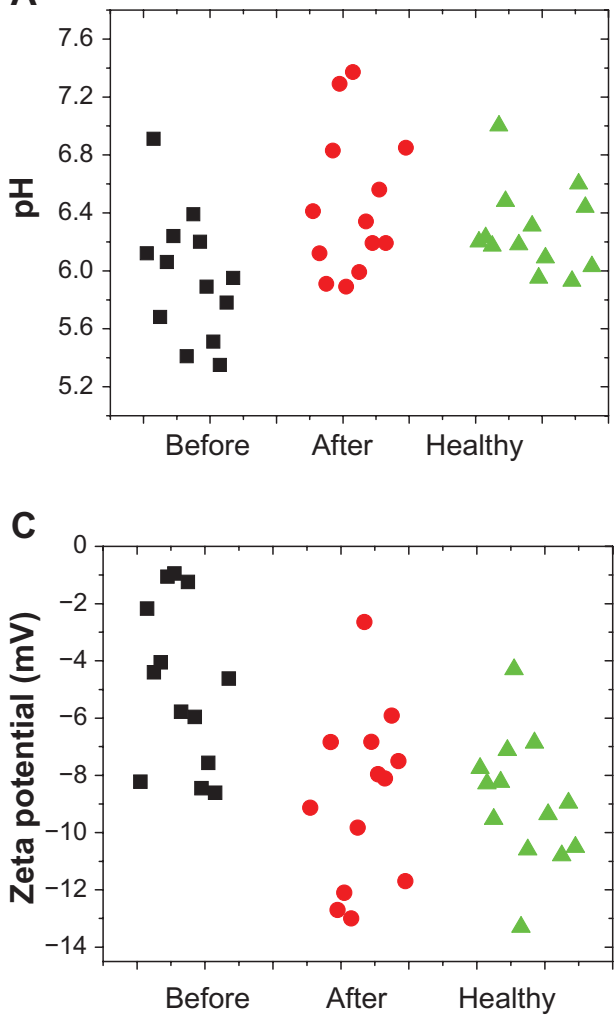

E

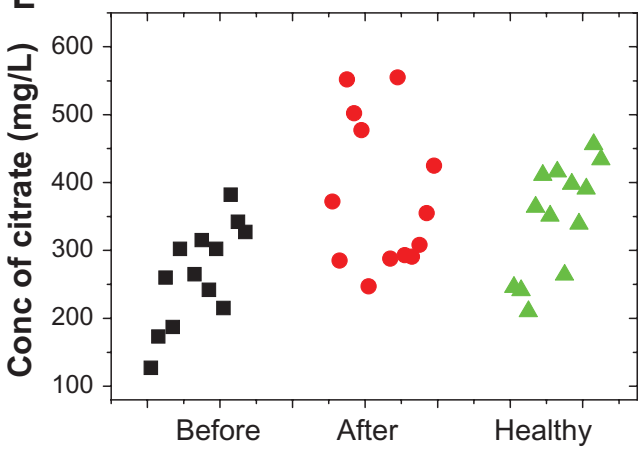

B

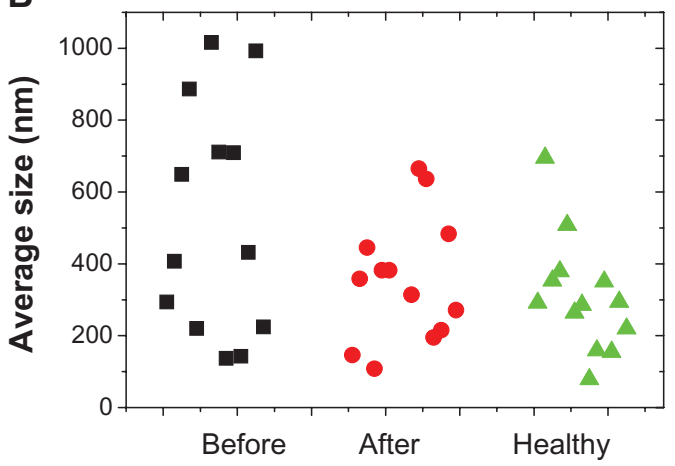

D
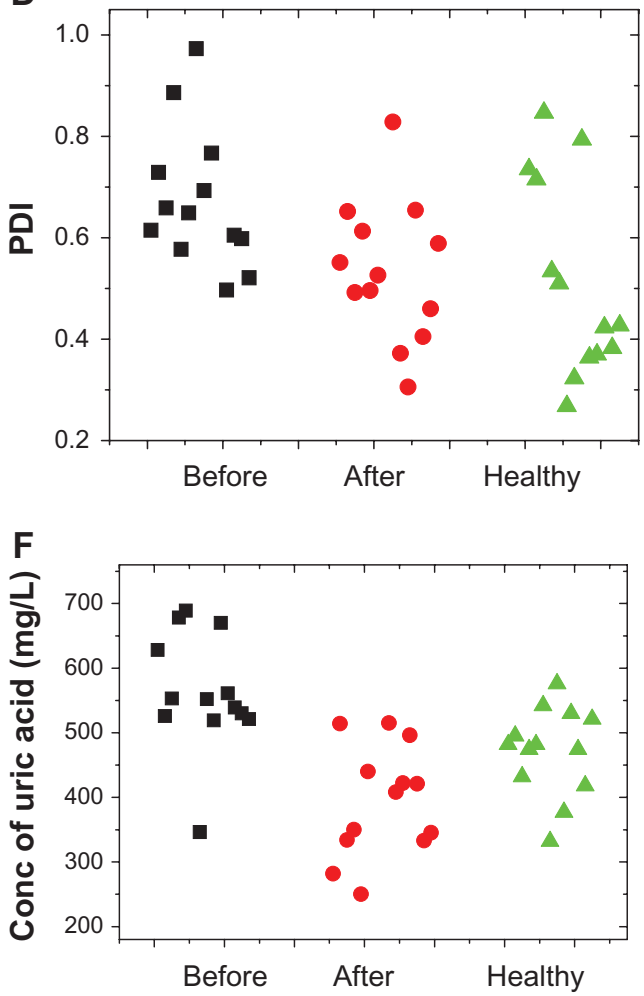

Figure 3 Comparison between the properties of urine and urinary crystallites from healthy controls and patients with $\mathrm{CaOx}$ stones before and after $\mathrm{K}_{3}$ cit intake: urinary $\mathrm{pH}(\mathbf{A})$; average particle size (B); $\zeta(\mathbf{C})$; PDI (D); amount of excreted citrate (E); and amount of excreted UA (F).

Note: $n=13$

Abbreviations: $\mathrm{CaOx}$, calcium oxalate; $\mathrm{K}_{3}$ cit, potassium citrate; $\zeta$, zeta potential; PDI, polydispersity index; UA, uric acid.

4. With increased $\mathrm{pH}$, the $\mathrm{OH}^{-}$ions in the urine increased. On the other hand, the crystallite surfaces were negatively charged because of the adsorbance of anionic inhibitors under a basic condition. Consequently, the thickness of the electric double-layer between the $\mathrm{OH}^{-}$ions and urinary crystallites increased. According to the DLVO colloid flocculation theory, the repulsive energy of the electric double layer depends on the thickness of the electric double layer. An increase in thickness of the electric double layer increases the repulsive energy, thereby leading to an increased absolute value of the $\zeta .{ }^{20,21}$
After the $\zeta$ of the urinary crystallite surfaces became negative, the electrostatic repulsion increased, thereby inhibiting the growth and aggregation of urinary crystallites. These anions also closed the growth sites of crystals to further inhibit crystal growth.

\section{Stability difference between urinary crystallites before and after $\mathrm{K}_{3}$ cit intake Intensity-autocorrelation curve changes}

The nanocrystallites particles in urine are in continuous Brownian movement. Brownian movement is a random fluc- 
Table I Comparison of the properties of urine and urinary crystallites from healthy controls and $\mathrm{CaOx}$ stone-forming patients before and after $\mathrm{K}_{3}$ cit intake $(\mathrm{n}=13)$

\begin{tabular}{|c|c|c|c|c|}
\hline & Before $K_{3}$ cit & After $K_{3}$ cit & Control & $P^{a}$ \\
\hline$\overline{\mathrm{K}_{3} \text { cit excretion, } \mathrm{mg} / \mathrm{L}}$ & $264 \pm 74$ & $381 \pm 109$ & $348 \pm 82$ & $P>0.05$ \\
\hline GAG excretion, $\mathrm{mg} / \mathrm{L}$ & $5.18 \pm 0.82$ & $11.81 \pm 1.62$ & $9.80 \pm 1.83$ & $P<0.05^{*}$ \\
\hline UA excretion, $\mathrm{mg} / \mathrm{L}$ & $563 \pm 91$ & $393 \pm 86$ & $472 \pm 68$ & $P>0.05$ \\
\hline Urine $\mathrm{pH}$ & $5.96 \pm 0.43$ & $6.46 \pm 0.50$ & $6.28 \pm 0.30$ & $P>0.05$ \\
\hline particle size, $\mathrm{nm}$ & $524 \pm 320$ & $354 \pm 173$ & $310 \pm 160$ & $P<0.05^{*}$ \\
\hline$\xi, \mathrm{mV}$ & $-4.85 \pm 2.87$ & $-8.77 \pm 3.03$ & $-8.89 \pm 2.23$ & $P>0.05$ \\
\hline PDI & $0.67 \pm 0.14$ & $0.53 \pm 0.19$ & $0.51 \pm 0.14$ & $P>0.05$ \\
\hline Decay time $T, \mathrm{~ms}$ & $11.4 \pm 3.2$ & $4.3 \pm 1.7$ & $2.8 \pm 0.7$ & $P<0.05^{*}$ \\
\hline
\end{tabular}

Notes: Values are shown as mean \pm standard deviation.

${ }^{a}$ Comparisons were made against $\mathrm{CaOx}$ stone patients before and after $\mathrm{K}_{3}$ cit intake. *Statistically significant comparisons.

Abbreviations: $\mathrm{CaOx}$, calcium oxalate; $\mathrm{K}_{3}$ cit, potassium citrate; GAG, gycosaminoglycans; UA, uric acid; $\xi$, zeta potential; PDI, polydispersity index.

tuation motion that denotes the rate of light intensity change in relation to particle size. A smaller particle corresponds to a faster Brownian movement, leading to a faster scattering intensity change and an inferior signal correlation as well as quick variations in the attenuation of curves. ${ }^{22-24} \mathrm{~A}$ faster
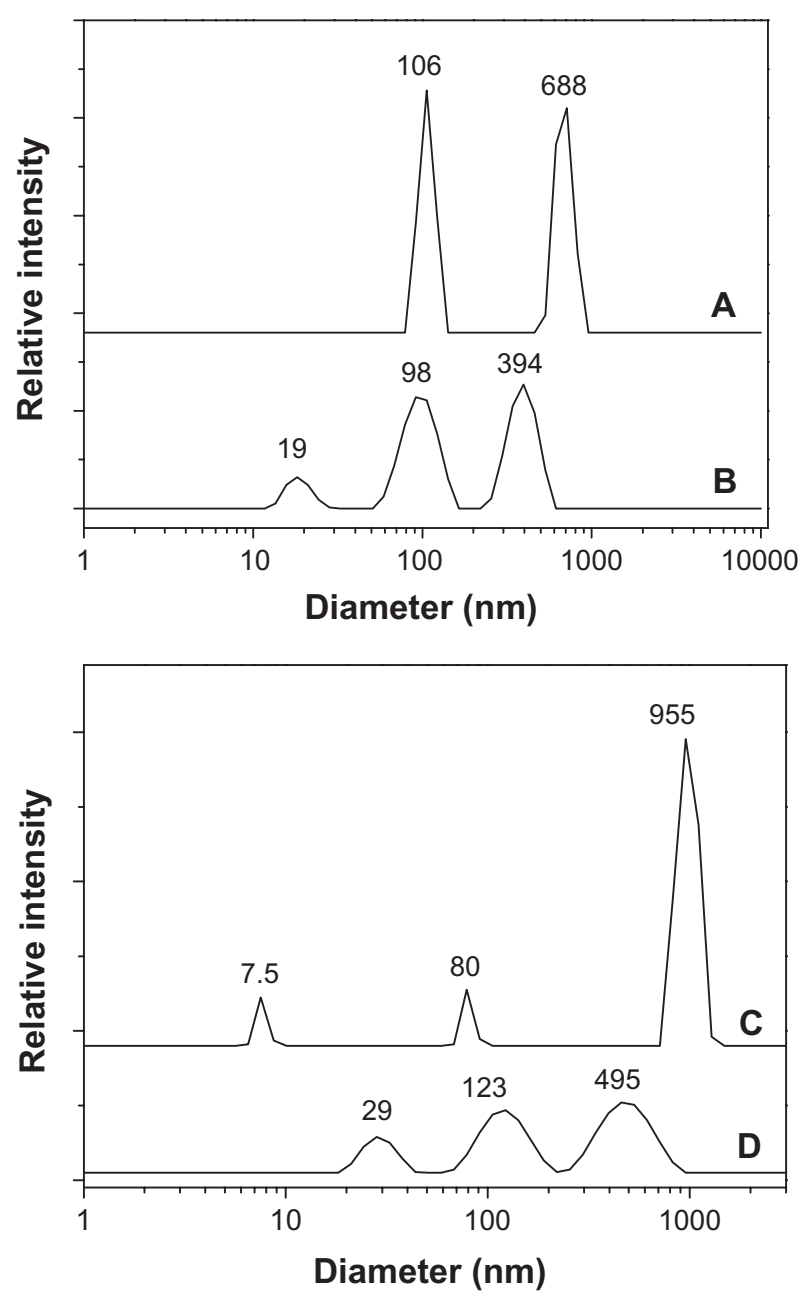

Figure 4 Particle size distribution of urinary crystallites of two $\mathrm{CaO}$ x stone patients before (A and $\mathbf{C}$ ) and after ( $\mathbf{B}$ and $\mathbf{D}) \mathrm{K}_{3}$ cit intake.

Abbreviations: $\mathrm{CaOx}$, calcium oxalate; $\mathrm{K}_{3}$ cit, potassium citrate. attenuation of the autocorrelation curve corresponds to a steeper curve and shorter decay time. By contrast, larger particles correspond to slower Brownian movement, leading to a slower scattering intensity change and corresponding in turn, to better signal correlations and slower attenuation of the autocorrelation curve.

Before $\mathrm{K}_{3}$ cit intake, the baseline of the intensityautocorrelation curves was coarser (Figure 5A) and the attenuation of the curves was slower. This result indicated that urine particles were larger before $\mathrm{K}_{3}$ cit intake or that aggregated crystallites existed, which conformed to the detection result of the particle size.

After $\mathrm{K}_{3}$ cit intake, the baseline of the intensityautocorrelation curves of the urine nanocrystallites was smoother, and the attenuation of the curves was faster (Figure 5B). The attenuation time was also reduced to $4.3 \pm 1.7 \mathrm{~ms}$ (Table 1). This result suggested that the particles of crystallites in urine were smaller.

\section{Polydispersity index (PDI) changes}

PDI is a parameter that characterizes the width of the particle size distribution. A smaller PDI value corresponds to a narrower particle size distribution range and more uniform particles for the tested sample. For standard samples or truly monodispersed samples, PDI $<0.05$, whereas PDI $=0.05-0.08$ if the samples are almost monodispersed. When the PDI $=0.08-0.7$, the samples are in moderate dispersion. The PDI of the sample values within this range is suitable for detection of particle size and particle size distribution, using a nanoparticle size analyzer. If the PDI $>0.7$ of the sample, the distribution range is too wide for a nanoparticle size analyzer, based on the principle of dynamic light scattering.

Before $\mathrm{K}_{3}$ cit intake, the PDI of the urinary crystallites of all stone formers was greater than 0.5 (Figure 3D), with an average value of $0.67 \pm 0.14$. This result indicated that the 
size of these crystallites was uneven, that the urine system was unstable, and that the crystallites easily aggregated. However, the PDI decreased to $0.53 \pm 0.19$ after $\mathrm{K}_{3}$ cit intake, indicating that the distribution range of the urinary crystallites became narrower and that the particle size was homogenized.

\section{Decay time changes}

As shown in Table 1, the order of decay time of the different kinds of urinary crystallites was as follows: the decay time in patients before $\mathrm{K}_{3}$ cit intake $(11.4 \pm 3.2 \mathrm{~ms})>$ the decay time in patients after $\mathrm{K}_{3}$ cit intake $(4.3 \pm 1.7 \mathrm{~ms})>$ the decay time in healthy controls $(2.8 \pm 0.7 \mathrm{~ms})$.

This result suggested that the average particle size of the urinary crystallites before $\mathrm{K}_{3}$ cit intake was larger than that after $\mathrm{K}_{3}$ cit intake. ${ }^{25,26}$ These results were attributed to the lower concentration and activity of inhibitors in the urine of stone-forming patients, preventing the adsorption of most crystallites by inhibitor molecules. A stronger electrostatic interaction also exists between these free crystallites; thus, these crystallites aggregated more easily than those of the controls. Compared with the urine before $\mathrm{K}_{3}$ cit intake, the aggregation degree of crystallites was reduced after $\mathrm{K}_{3}$ cit intake, thus reducing the risk of stone formation.

After the absolute $\zeta$ value on the crystallite surfaces increased, the electrostatic repulsive forces also increased, and the particles were not easy to aggregate. Therefore, $\mathrm{K}_{3}$ cit increased the stability of the urine system and reduced calculus formation.

\section{Changes in appearance of urinary crystallites before and after $\mathrm{K}_{3}$ cit intake}

As shown in Figure 6, the TEM detection results further confirmed the above results. Urinary crystallites from $\mathrm{CaOx}$ stone formers before $\mathrm{K}_{3}$ cit intake exhibited sharp edges and corners, large size differences ranging from a few nanometers to $1000 \mathrm{~nm}$, and significant aggregation of crystallites (Figure 6A and B). After $\mathrm{K}_{3}$ cit intake, the crystallites became blunt, decreased in size, and showed less aggregation (Figure 6C and D). The changes in appearance and size of the urinary crystallites before and after $\mathrm{K}_{3}$ cit intake were due to the following four reasons:

1. First, the $\mathrm{K}_{3}$ cit concentration increased in the urine after $\mathrm{K}_{3}$ cit intake. $\mathrm{K}_{3}$ cit is a chelating agent. It can combine with $\mathrm{Ca}^{2+}$ ions in urine to form soluble calcium citrate and reduce the $\mathrm{Ca}^{2+}$ ion concentration and $\mathrm{CaOx}$ saturation in urine. After the $\mathrm{CaOx}$ saturation decreased, the deposited $\mathrm{CaOx}$ crystallites decreased, and the growth and aggregation of $\mathrm{CaOx}$ crystallites were also inhibited. Thus, the size of urinary crystallites was reduced.

2. The increase in urine $\mathrm{pH}$ not only transformed UA into urate, whose solubility is much larger than that of UA, but also decreased UA deposition. The increase in urine $\mathrm{pH}$ also decreased the heterogeneous nucleation of $\mathrm{CaOx}$ crystals, as these are often caused by UA crystals. $^{27}$

3. A strong precipitation-dissolution equilibrium existed between $\mathrm{K}_{3}$ cit and $\mathrm{CaOx}$ crystallites. The $\mathrm{Ca}^{2+}$ ions on

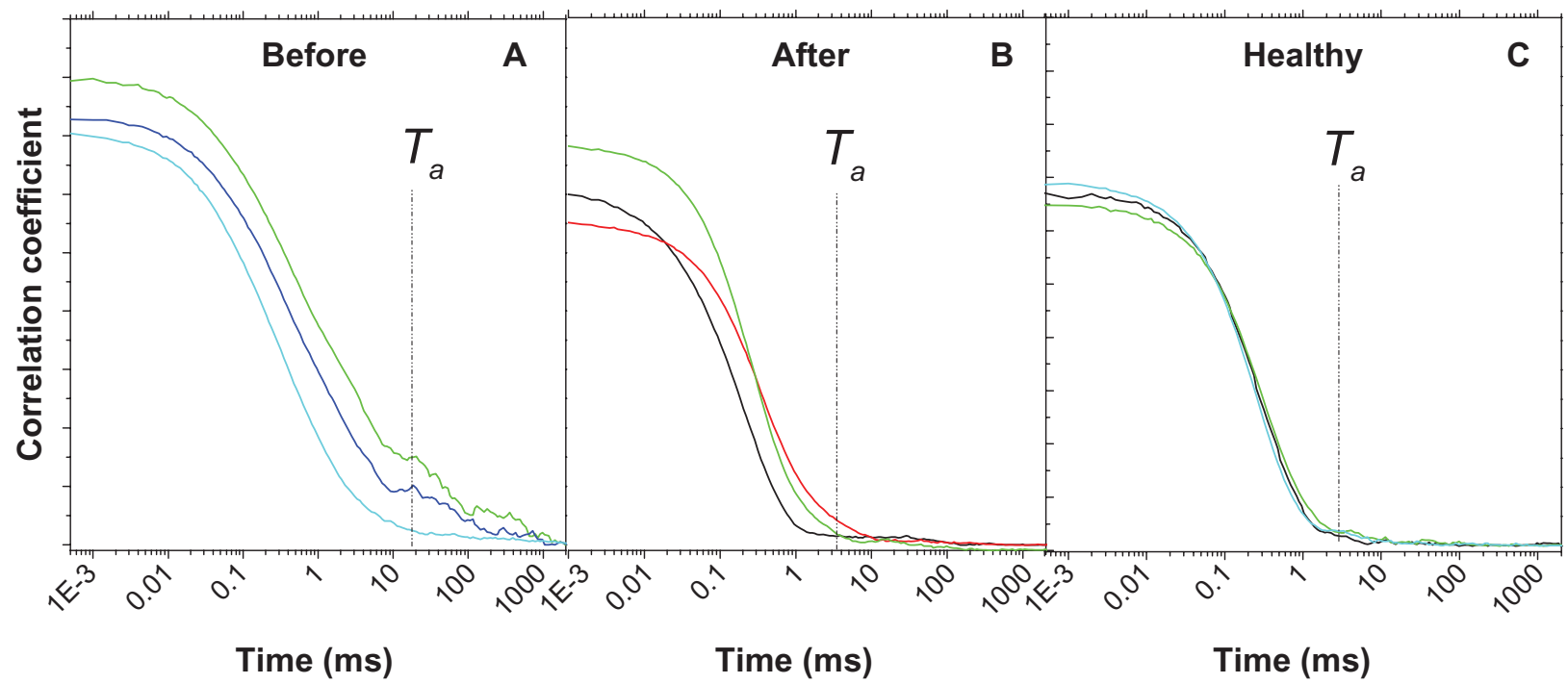

Figure 5 Attenuation curve of the intensity autocorrelation function of urinary crystallites from three patients with $\mathrm{CaOx}$ stones before $(\mathbf{A})$ and after $(\mathbf{B}) \mathrm{K}_{3}$ cit intake, and three healthy controls (C).

Abbreviations: $\mathrm{CaOx}$, calcium oxalate; $\mathrm{K}_{3}$ cit, potassium citrate; $T_{a}$, decay time. 
A

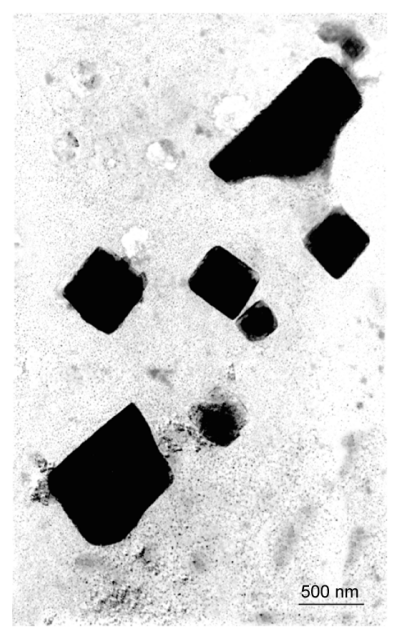

C

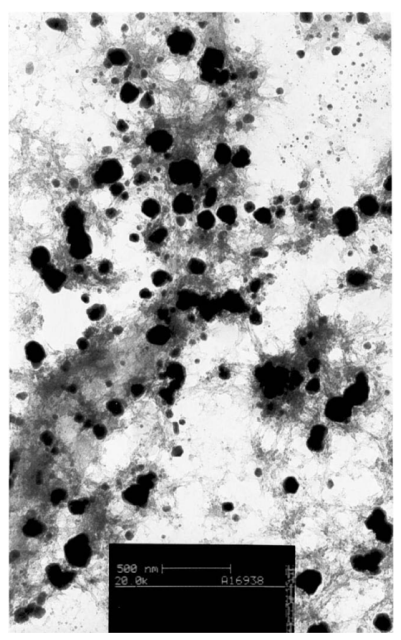

B

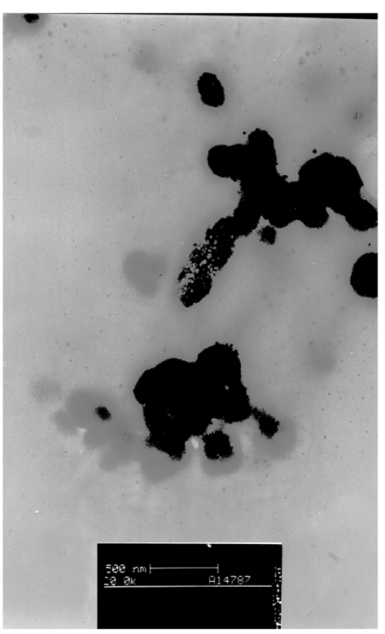

D

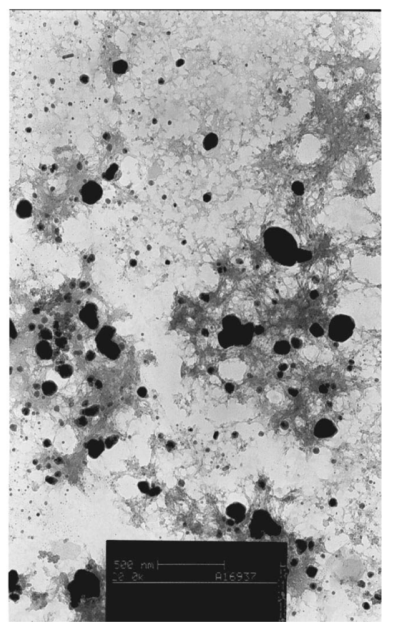

Figure 6 TEM images of urinary nanocrystallites of two $\mathrm{CaOx}$ stone-forming patients before (A and $\mathbf{B})$ and after $(\mathbf{C}$ and $\mathbf{D}) \mathrm{K}_{3}$ cit intake.

Note: Bar: $500 \mathrm{~nm}$.

Abbreviations: TEM, transmission electron microscope; $\mathrm{CaOx}$, calcium oxalate; $\mathrm{K}_{3}$ cit, potassium citrate.

the surface of $\mathrm{CaOx}$ crystallites, particularly the $\mathrm{Ca}^{2+}$ ions on the peripheries and edges, were constantly dissolved by $\mathrm{K}_{3}$ cit. The dissolved $\mathrm{Ca}^{2+}$ ions also constantly precipitated to the surface of crystallites. This continuous precipitation-dissolution process made the crystallites blunt (Figure 6C and D).

4. The increase in $\mathrm{pH}$ can strengthen the inhibitory activity of some components in urine, such as TH protein and pyrophosphate..$^{28,29} \mathrm{TH}$ protein plays dual roles in $\mathrm{CaOx}$ crystallite aggregation. $\mathrm{TH}$ protein promotes crystallite aggregation at lower $\mathrm{pH}$ but inhibits aggregation at higher pH. ${ }^{19}$ Accordingly, in this study, the aggregation of urinary crystallites decreased after $\mathrm{K}_{3}$ cit intake. Therefore, the increase in urinary $\mathrm{pH}$ was conducive to the prevention of $\mathrm{CaOx}$ stone formation.

\section{Conclusion}

The main components of the urinary crystallites of $\mathrm{CaOx}$ stone-forming patients were UA, COM, and $\beta$-calcium phosphate. Before $\mathrm{K}_{3}$ cit intake, the edges and corners of the crystallites were sharp, their sizes ranged from a few nanometers to $1000 \mathrm{~nm}$, and they showed significant aggregation. By contrast, at 1 week post- $\mathrm{K}_{3}$ cit intake, the urine $\mathrm{pH}$ increased, the species and mass of urinary crystallites significantly decreased, the crystallite morphology became blunt, the absolute value of $\zeta$ on the crystallite surface increased, the average size of crystallites decreased, and the aggregation of crystallites significantly decreased. All these changes helped inhibit the urinary crystallite deposition and $\mathrm{CaOx}$ stone formation.

\section{Acknowledgments}

This research was supported by the Natural Science Foundation of China (81170649).

\section{Disclosure}

The authors report no conflicts of interest in this work.

\section{References}

1. Grohe B, Hug S, Langdon A, et al. Mimicking the biomolecular control of calcium oxalate monohydrate crystal growth: effect of contiguous glutamic acids. Langmuir. 2012;28(33):12182-12190.

2. Yao XQ, Ouyang JM, Peng H, Zhu WY, Chen HQ. Inhibition on calcium oxalate crystallization and repair on injured renal epithelial cells of degraded soybean polysaccharide. Carbohydr Polymers. 2012;90(1): 392-398.

3. Peng H, Ouyang JM, Yao XQ, Yang RE. Interaction between submicron COD crystals and renal epithelial cell. Int J Nanomed. 2012;7: 4727-4737.

4. Daudon M, Hennequin C, Boujelben G, Lacour B, Jungers P. Serial crystalluria determination and the risk of recurrence in calcium stone formers. Kidney Int. 2005;67(5):1934-1943.

5. He JY, Deng SP, Ouyang JM. Morphology, particle size distribution, aggregation, and crystal phase of nanocrystallites in urine of healthy persons and lithogenic patients. IEEE Trans Nanobioscience. 2010;9(2): 156-163.

6. Gui BS, Huang ZJ, Xu XJ, Li MR, He JY, Ouyang JM. Measurement of urine crystallites and its influencing factors by nanoparticle size analyzer. J Nanosci Nanotechnol. 2010;10(8):5232-5241.

7. Mechlin C, KalorinC, Asplin J, White M, Splenda ${ }^{\circledR}$. Improves tolerance of oral potassium citrate supplementation for prevention of stone formation: results of a randomized double-blind trial. J Endourol. 2011;25(9):1541-1545.

8. Fuselier HA, Moore K, Lindberg J, et al. Agglomeration inhibition reflected stone-forming activity during long-term potassium citrate therapy in calcium stone formers. Urology. 1998;52(6):988-994.

9. Whiteman $P$. The quantitative determination of glycosaminoglycans in urine with Alcian Blue 8GX. Biochem J. 1973;131(2):351-357.

10. Ding S-F, Jin H-M, Zhu SP. Catalytic activation dynamic determination of citric acid. Chin J Health Lab Tech. 2009;19(7):1520-1521.

11. Zuo Y, Wang C, Zhou J, Sachdeva A, Ruelos VC. Simultaneous determination of creatinine and uric acid in human urine by high-performance liquid chromatography. Anal Sci. 2008;24(12): 1589-1592. 
12. King M, McClure WF, Andrews LC. Powder Diffraction File Alphabetic Index, Inorganic Phases/Organic Phases. Newtown Square: International Center for Diffraction Data; 1992.

13. Jin Y, Sun XS, Xue J. X-ray Diffraction Analysis Techniques. Beijing: National Defence Industrial Press; 2008.

14. Cytron S, Kravchick S, Sela BA, et al. Fiberoptic infrared spectroscopy: a novel tool for the analysis of urine and urinary salts in situ and in real time. Urology. 2003;61(1):231-235.

15. Benramdane L, Bouatia M, Idrissi MOB, Draoui M. Infrared analysis of urinary stones, using a single reflection accessory and a $\mathrm{KBr}$ pellet transmission. Spectrosc Lett. 2008;41(2):72-80.

16. Jing Z, GuoZeng W, Ning J, JiaWei Y, Yan G, Fang Y. Analysis of urinary calculi composition by infrared spectroscopy: a prospective study of 625 patients in eastern China. Urol Res. 2010;38(2):111-115.

17. Frost RL, Xi Y, Scholz R, Belotti FM, Alberto Dias Menezes Filho L. Raman and infrared spectroscopic characterization of beryllonite, a sodium and beryllium phosphate mineral-implications for mineral collectors. Spectrochim Acta Biomol Spectrosc. 2012;97:1058-1062.

18. Verdesca S, Fogazzi GB, Garigali G, Messa P, Daudon M. Crystalluria: prevalence, different types of crystals and the role of infrared spectroscopy. Clin Chem Lab Med. 2011;49(3):515-520.

19. Hess B, Zipperle L, Jaeger P. Citrate and calcium effects on Tamm-Horsfall glycoprotein as a modifier of calcium oxalate crystal aggregation. Am J Physiol. 1993;265(6 Pt 2):F784-F791.

20. Song X, Jiang N, Li Y, Xu D, Qiu G. Synthesis of $\mathrm{CeO}_{2}$-coated $\mathrm{SiO}_{2}$ nanoparticle and dispersion stability of its suspension. Mater Chem Phys. 2008;110:128-135.
21. Deng XC, Luo JS, Tang YJ, Han SJ, Li K, Zhang HL. Dispersion and classification of nano-cu powder. Metallic Functional Materials. 2010;(3):37-41.

22. Frisken B. Revisiting the method of cumulants for the analysis of dynamic light-scattering data. Appl Opt. 2001;40(24):4087-4091.

23. Gui BS, Huang ZJ, Xu XJ, Li MR, He JY, Ouyang JM. Measurement of urine crystallites and its influencing factors by nanoparticle size analyzer. J Nanosci Nanotechnol. 2010;10(8):5232-5241.

24. Lin HM, Shao YH, Qu JL, Yin J, Chen SP, Niu HB. Study on wide-field fluorescence sectioning microscopy based on dynamic speckle illumination. Acta Phys Sin. 2008;57(12):7641-7649.

25. Kinjo M, Sakata H, Mikuni S. Fluorescence correlation spectroscopy example: shift of autocorrelation curve. Cold Spring Harb Protoc. 2011; 10:1267-1269.

26. Murphy DL, Beretvas SN, Pituch KA. The effects of autocorrelation on the curve-of-factors growth model. Struct Equ Modeling. 2011;18(3): $430-448$.

27. Allie S, Rodgers A. Effects of calcium carbonate, magnesium oxide and sodium citrate bicarbonate health supplements on the urinary risk factors for kidney stone formation. Clin Chem Lab Med. 2003;41(1):39-45.

28. Pak CY. Citrate and renal calculi: an update. Miner Electrolyte Metab. 1994;20(6):371-377.

29. Caudarella R, Vescini F. Urinary citrate and renal stone disease: the preventive role of alkali citrate treatment. Arch Ital Urol Androl. 2009; 81(3):182-187.
International Journal of Nanomedicine

\section{Publish your work in this journal}

The International Journal of Nanomedicine is an international, peerreviewed journal focusing on the application of nanotechnology in diagnostics, therapeutics, and drug delivery systems throughout the biomedical field. This journal is indexed on PubMed Central, MedLine, CAS, SciSearch ${ }^{\circledR}$, Current Contents ${ }^{\circledR} /$ Clinical Medicine,

\section{Dovepress}

Journal Citation Reports/Science Edition, EMBase, Scopus and the Elsevier Bibliographic databases. The manuscript management system is completely online and includes a very quick and fair peer-review system, which is all easy to use. Visit http://www.dovepress.com/ testimonials.php to read real quotes from published authors. 